ENCYCIOPEDDE Encyclopédie berbère

BERBERE

$35 \mid 2013$

35| Oasitae - Ortaïas

\title{
Ortaïas, chef Maure du Hodna au vi siècle
}

\author{
J.-P. Laporte
}

\section{OpenEdition}

Journals

\section{Édition électronique}

URL : https://journals.openedition.org/encyclopedieberbere/2832

DOI : 10.4000/encyclopedieberbere.2832

ISSN : 2262-7197

\section{Éditeur}

Peeters Publishers

\section{Édition imprimée}

Date de publication : 1 juin 2013

Pagination : 5856-5858

ISBN : 978-2-7584-0184-1

ISSN : $1015-7344$

\section{Référence électronique}

J.-P. Laporte, «Ortaïas, chef Maure du Hodna au vi siècle », Encyclopédie berbère [En ligne], 35 | 2013, document O29, mis en ligne le 12 mars 2021, consulté le 17 février 2022. URL : http:// journals.openedition.org/encyclopedieberbere/2832 ; DOI : https://doi.org/10.4000/ encyclopedieberbere.2832

Ce document a été généré automatiquement le 17 février 2022.

(c) Tous droits réservés 


\title{
Ortaïas, chef Maure du Hodna au $\mathrm{VI}^{\mathrm{e}}$ siècle
}

\author{
J.-P. Laporte
}

1 L'histoire d'Ortaias, chef du Hodna* au VI ${ }^{e}$ siècle, a longtemps été obscurcie par son identification avec le Vartaia dédicant de l'épitaphe de Masties*, identification qui posait bien inutilement des problèmes historiques considérables et amenait à des hypothèses et à des conclusions fort variées (en dernier lieu P. Morizot 1989; cf. tableau synthétique dans Modéran 2003, p. 379). La conclusion d'Y. Modéran est particulièrement nette : il faut distinguer les deux personnages (Modéran 2003, p. 377, 392 n. 323 et 352-361, 382, 412). Il n'y a aucune chance qu'Ortaias ait eu accès au centre de l'Aurès, contrôlé par son ennemi Iaudas*, pour ajouter deux lignes d'hommage à l'épitaphe de Masties une trentaine d'années après la mort de ce dernier, de plus, sans se parer lui-même (par humilité!) de quelque titre que ce soit. Ortaias et Vartaia étaient de simples homonymes, ce qui ne pose aucune difficulté, surtout lorsque deux personnages portent un nom répandu.

2 En effet, Ortaias est certainement un nom berbère de type bien attesté, formé sur le préfixe négatif WAR, «sans... », fréquent dans l'Antiquité, abondant au Moyen Age (Chaker 1985, p. 494) et d'un radical Taya de sens encore inconnu. Les noms ou surnoms commençant comme cela sont présents dans toutes les langues ("Sans peur », "Sans terre », etc.).

3 Au moment du débarquement byzantin de 533 , Ortaias régnait sur un royaume berbère situé entre l'Aurès d'Iaudas* à l'est et la Maurétanie de Mastigas/Mastinas* à l'ouest (Procope, II, 13, 19). Il était limité au sud par le désert, sans doute au sud-ouest par des populations d'hommes blonds à la peau très blanche (Procope, II, 13, 29), habitant probablement les monts des Ouled Naïl.

4 La partie centrale de ce royaume paraît avoir couvert le nord/nord-est du Hodna, sur la partie méridionale de l'ancienne Maurétanie sitifienne et une petite partie de l'ouest de l'ancienne Numidie. P. Marizot (1993, p. 98-99) a attiré l'attention sur un toponyme

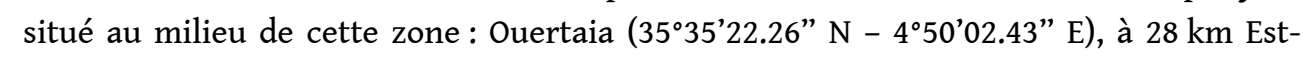
Sud-Est de M'sila et $53 \mathrm{~km}$ Nord-Nord-Est de Tobna (Gsell, Atlas, f. 26, nº 89 à 91), 
secteur où ont d'ailleurs été trouvés plus récemment quelques fragments de lampes chrétiennes $\mathrm{du} \mathrm{VI}^{\mathrm{e}}$ siècle. Le toponyme est linguistiquement très proche du nom d'Ortaias. Cela ne serait pas le premier exemple de chef désigné par un nom de lieu ou inversement (Mazuca, fundus Mazucamus, Mazouna...). L'hypothèse semble forte. Ce territoire avait été autrefois romain. En 421 Boniface, établi à Thubunae (Tobna*), le défendait encore victorieusement contre les tribus du sud et du sud-ouest, avant que son départ puis sa révolte de 427 contre Ravenne ne le laissent entre leurs mains. Les Maures qui s'y installèrent furent peut-être les ancêtres de ceux que commandait Ortaias. Toutefois, point n'est besoin d'imaginer une migration de grande ampleur. Il suffisait d'une classe de dirigeants maures pour remplacer les dirigeants romains, alors que l'essentiel de la population déjà berbéro-romaine restait en place. À l'époque vandale, ce territoire était officiellement maure, avec les cités de Thubunae, Macri et une Nippis inconnue (pour nous Nicivibus/N'gaous*). En 483-4, Hunéric y exila 4966 catholiques, en les confiant à la garde de rois berbères sans doute païens. Les exilés firent probablement avancer le message de l'Evangile dans la région. Souvent chrétiens au début du VI ${ }^{e}$ siècle, tous les grands chefs des " Maures de l'intérieur », contrôlaient en réalité des populations nombreuses de sédentaires maures romanisés et christianisés à côté de nomades et semi-nomades souvent restés païens.

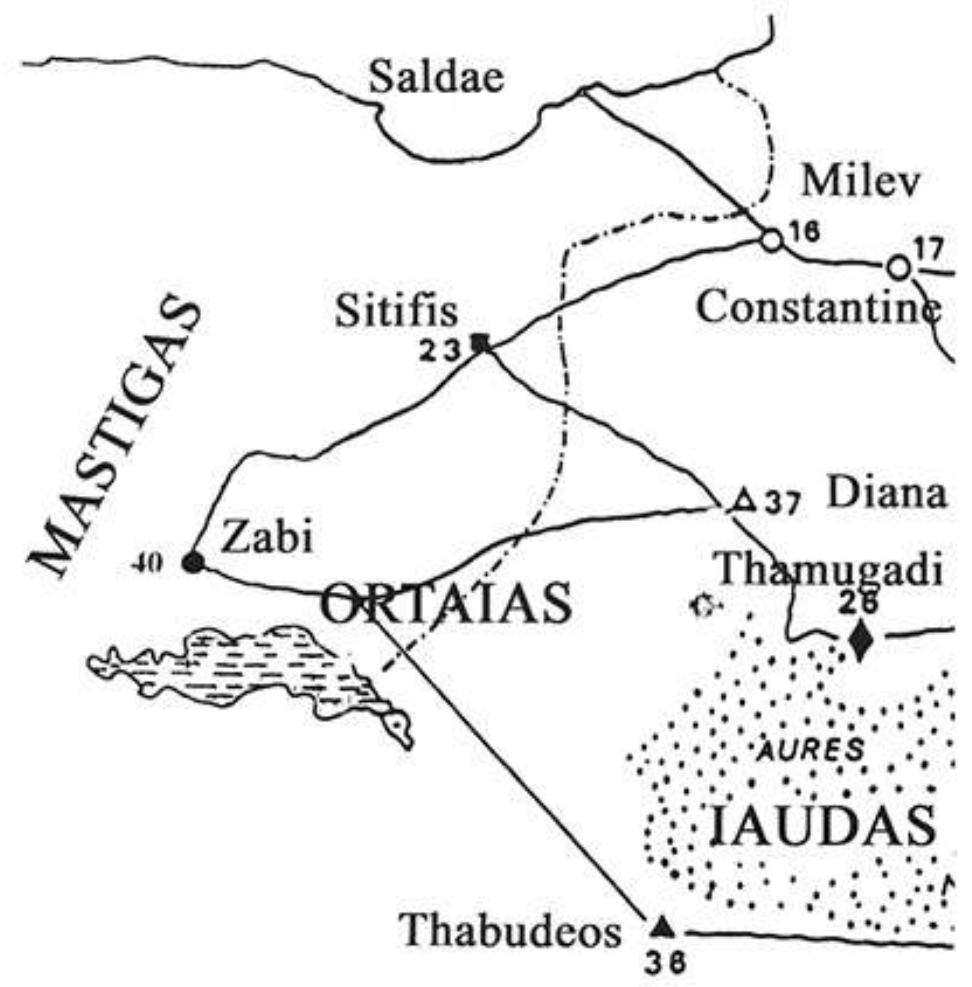

FIg. 1 : LOCALISATION PROBABLE DU TERRITOIRE D'ORTAIAS. SUR UN FOND DE CARTE Y. MODÉRAN, 2003, P. 600.

D'un point de vue diplomatique et militaire régional, le territoire d'Ortaias apparaissait en 533-534 comme menacé à la fois par l'Aurasien Iaudas et le Maurétanien Mastigas, qui comptaient bien expulser Ortaias et ses Maures de territoires qu'ils gouvernaient depuis longtemps (Procope, II, 13, 19). Sur la défensive, Ortaias ne pouvait que rechercher l'alliance byzantine, tout comme un autre chef nommé Massonas, dont on ne connaît hélas pas la situation géographique (peut-être à l'est de l'Aurès). 
6 Procope a rencontré Ortaias (II, 13, 29 : «j'ai entendu cet homme dire »). Cette entrevue a dû avoir lieu entre le débarquement byzantin de 533 et, au plus tard, la mutinerie de l'armée byzantine conduite par Stotzas* en 536, pendant laquelle Procope quitta l'Afrique avec Solomon. On ne sait pas où, soit à Carthage où il se serait rendu pour demander alliance et protection en fin 534/début 535, soit au début de la première campagne byzantine de 535 contre l'Aurès.

7 L'allégeance générale et spontanée des chefs maures qui avait suivi le débarquement byzantin (Procope, II, 25, 38) ne doit pas faire illusion. Loin de se soumettre réellement, en acceptant une suzeraineté qu'ils espéraient lointaine, ils attendaient au contraire la confirmation de leur pouvoir traditionnel. Ils comptaient bien mettre à profit toute faiblesse des Byzantins (Procope, II, 8, 18-20). Si ces derniers accédèrent tout d'abord à leur demande, le temps de consolider leur propre position, ils ne renonçaient pas in petto à reconquérir tous les anciens territoires romains, comme allait le montrer la suite.

8 En 535, Ortaias, certainement heureux de voir les Byzantins s'attaquer à son ennemi Iaudas, se rangea dans leur camp pour l'attaque de l'Aurès, mais Solomon s'en méfiait (comme d'ailleurs des autres Maures). Et c'est pour cela, et parce qu'ils avaient mal préparé l'expédition (Procope, II, 13, 30-38) que les Byzantins durent cesser l'offensive et se retirer au bout de dix jours de marche.

9 Les intentions probablement transparentes des autorités byzantines constituaient pour les Maures, mêmes alliés, un danger suffisant pour rapprocher Ortaias et Iaudas. En 536 , ils se trouvèrent tous les deux côte à côte en arrière (et en principe en soutien) de l'armée du révolté byzantin Stotzas (Procope, II, 17, 8). Mais dans les faits, ils attendaient tous deux l'issue de la bataille pour se rallier au vainqueur et piller le camp du vaincu (Procope, II, 17, 11), qui fut Stotzas.

En 539, Ortaias ne semble avoir joué aucun rôle lors du raid victorieux de Solomon contre les possessions de Iaudas (Procope, II, 20, 22). On peut même penser que, dans la foulée de l'expédition byzantine, son royaume fut amputé au moins de sa partie septentrionale, dans la mesure où Solomon fit "rentrer dans le pouvoir romain » le pays de Zabè (Procope, II, 20, 30, avec une occupation de Zabi, près de M'sila, dont on connaît la dédicace sous Justinien et Théodora (CIL, VIII, 8805 ; Laporte 2003, p. 153-154, fig.). Peut-être balayé par les Byzantins, le royaume d'Ortaias disparut ou du moins on n'en a plus de traces.

\section{BIBLIOGRAPHIE}

CHAKER S., « Onomastique berbère ancienne : rupture et continuité », BCTH, ns, 19 B, 1985, p. $483-498$.

LAPORTE J.-P., « Zabi, Friki : notes sur la Maurétanie et la Numidie de Justinien », (Colloque L'Afrique vandale et Byzantine, Tunis, octobre 2000) = Antiquité Tardive, t. 11 (2003), p. 151-167. 
MODERAN Y. :

2003 : Les Maures et l'Afrique romaine, EFR, 2003.

2010 : “Mastigas (Mastinas)”, EB, XXX, 2010, p. 4673-4675.

MORIZOT P., « Pour une nouvelle lecture de l'elogium de Masties », Antiquités africaines, 25, 1989, p. 263-284.

MORIZOT P., « Recherches sur les campagnes de Solomon en umidie méridionale », CRAI, 1993, p. 83-107.

INDEX

Mots-clés : Antiquité, Aurès, Byzantins, Personnage, Vandales 